\title{
Frequency of primary central nervous system tumors in a tertiary hospital, Cairo, Egypt
}

\author{
Iman Hewedi ${ }^{1, *}$, Riham Ibrahim² ${ }^{2}$ Tarek Elserry ${ }^{3}$, Nourhan Taha $^{4}$, Hadeer Mohamed $^{5}$, Mohammed Hassan $^{6}$, \\ Hagar Attia ${ }^{7}$, Khaled Abd Elaziz ${ }^{8}$
}

${ }^{1,8}$ Professor (M.D), ${ }^{2}$ Lecturer (MD), ${ }^{3}$ Assistant Professor (MD), ${ }^{4,5,6,7}$ M.B.B.C.H, ${ }^{1,2}$ Dept. of Pathology, ${ }^{3}$ Dept. of Neurosurgery, ${ }^{4,5,6,7}$ Faculty of Medicine, ${ }^{8}$ Dept. of Community, Environmental and Occupational Medicine, Ain Shams University, Cairo, Egypt

*Corresponding Author:

E-mail: iman_hewedi@med.asu.edu.eg

\begin{abstract}
Introduction: In Egypt, few epidemiologic reports have highlighted the national and regional epidemiologic data regarding primary CNS tumors. In this study we aim to identify the frequency of various primary CNS tumors and to demonstrate the age group distribution, gender, topographic data and the different histopathologic types among our patients.

Materials and Methods: Data on all cases of primary CNS neoplasms received at Pathology department of Ain Shams University Specialized hospital in addition to a referral neuropathology lab during the period from 2010 to 2015 were collected with a total number of 996 cases. The patients were divided according to their age into two main groups, pediatric group including children and adolescents (from 0-18 years), and adult group ( $>18$ years). Patients' demographic data and histopathologic tumor types were analyzed.

Result: Frequency of primary CNS tumors among males was higher than females (51.7\% vs. $49.3 \%$ respectively). Regarding patient age, frequency among adults was $(89.4 \%)$ compared to pediatric age group $(10.6 \%)$. Gliomas were the most common primary CNS tumors in adults $(35 \%)$ followed by meningiomas $(33.3 \%)$ then pituitary adenomas $(15.6 \%)$; while in pediatric group embryonal tumors $(17 \%)$ were the second most common following gliomas $(59.4 \%)$.

Conclusion: This study highlighted the frequency, spectrum and prominent features of primary CNS tumors among Egyptian patients, in comparison to many worldwide reports. This study recommends the establishment of specialized national center for CNS tumors in Egypt; this will provide efficient registry system and accurate data analysis for these tumors.
\end{abstract}

Keywords: Epidemiology, CNS tumors, Egypt, Pediatric, Glioma, Meningioma.

\section{Introduction}

Primary central nervous system (CNS) tumors are relatively not common, their overall incidence is estimated as 19.34/100,000 persons per year. Generally, males are reported to have higher rates of primary malignant CNS tumors; however, females have higher rates of benign tumors, including meningioma. Among pediatric population, primary CNS tumors constitute about $20 \%$ of all solid tumors, only preceded by leukemia. ${ }^{1}$

In Egypt, few epidemiologic reports have highlighted the national and regional incidence of primary CNS tumors; one population-based study reported their overall incidence to be 5.34\%, 7.25\%, $4.49 \%$ in Upper, Middle and Lower Egypt, respectively. ${ }^{2}$

This study showed that the calculated incidence rate of brain tumors and nervous tissue was 6.9 for males and 5.8 for females with an age standardized incidence rate of 9.0 in 100.000 males and 8.0 in 100.000 females. $^{2}$

The fact that primary CNS tumors are not frequent, renders the data obtained from their epidemiologic studies crucial, in order to recognize the burden of the disease and to provide an insight for understanding its heterogeneity and time trend variation. The results of similar reports are essentially useful for planning the health care modalities and future research in given community. ${ }^{4}$

In this study, we elucidate the frequency distribution of primary CNS tumors in a single hospital, which represents a tertiary health care referral center, serving patients from different geographic locations of the country. We aim to identify the frequency of primary CNS tumors and to demonstrate the age group distribution, gender preference, topographic data and the different histopathologic types.

\section{Materials and Methods}

The study is retrospective study and the data was obtained from the archive of pathology department at Ain Shams University Specialized Hospital in addition to data from a referral histopathology laboratory Cairo, Egypt. The data collection targeted six years from January 2010 to December 2015. The confidentiality of patient information was strictly maintained while reviewing these data sets. Basic information such as the patient demographic data and tumor location were retrieved to be analyzed. The patients were divided according to their age into two main groups, pediatric group including children and adolescents (from 0-18 years), and adult group (> 18 years).

This study was designed to include all primary CNS tumors that arise from the brain and spinal cord, in 
addition to the meninges, pineal gland and cranial nerves, as described by the International Classification of Diseases (ICD-O-3), ${ }^{4}$ we also included pituitary gland tumors as well as cases of primary CNS lymphoma. The histopathologic tumor types and grades were revised and adjusted according to the most recent WHO classification of CNS tumors $2016 .{ }^{5}$ Our analysis excluded the data of metastatic tumors and nonneoplastic lesions.

\section{Statistical Methods}

Data entry was done on Microsoft Excel. Double data entry was performed. Data checking and data cleaning was done after data entry. Data analysis was done with SPSS program version 20.0

Chi-square test was used in the analysis of the results. A $\mathrm{P}$ value $<0.05$ was considered statistically significant.

\section{Ethical Consideration}

Ethical approval of the committee of the faculty of medicine, Ain Shams University was obtained. Total anonymity of the collected data was maintained throughout the study.

\section{Results}

Between the years 2010 and 2015, 996 cases of primary CNS tumors were diagnosed in the Pathology Department of Ain Shams University Specialized Hospital in addition to the referral lab. Gliomas represented the most frequent tumor in our population accounting for $(35 \%)$, followed by meningioma $(33.3 \%)$ and pituitary adenoma $(15.6 \%)$.

Distribution of Tumors According to Patients' Age Table (1): comparison between age groups of the patients and type of CNS tumors

\begin{tabular}{|l|c|c|c|c|c|c|c|c|c|}
\hline Age group & $\begin{array}{c}\text { Glioma } \\
\text { No. \% }\end{array}$ & $\begin{array}{c}\text { Meningioma } \\
\text { No. \% }\end{array}$ & $\begin{array}{c}\text { Mesenchymal } \\
\text { non mening } \\
\text { No. \% }\end{array}$ & $\begin{array}{c}\text { Lymphoid } \\
\text { No. \% }\end{array}$ & $\begin{array}{c}\text { Neuronal } \\
\text { No. \% }\end{array}$ & $\begin{array}{c}\text { Pituit } \\
\text { Adenoma } \\
\text { No. \% }\end{array}$ & $\begin{array}{c}\text { Embrynonal } \\
\text { No. \% }\end{array}$ & $\begin{array}{c}\text { Nerve sheath } \\
\text { No. \% }\end{array}$ & $\begin{array}{c}\text { Miscellaneous } \\
\text { No. \% }\end{array}$ \\
\hline$<=18 \mathrm{~N}=106$ & 6359.4 & 10.9 & 0 & 0 & 43.8 & 32.8 & 1817.0 & 21.9 & 1514.2 \\
\hline$>18 \mathrm{~N}=890$ & 28632.1 & 33137.2 & 60.7 & 222.5 & 60.7 & 15217.1 & 131.5 & 475.3 & 273.0 \\
\hline
\end{tabular}

\section{$\mathrm{X} 2=\mathbf{1 8 5 . 5} \mathrm{P}=\mathbf{0 . 0 0 0}$}

The distribution of cases belonging to each tumor histopathologic type among pediatric and adult populations is illustrated in Fig. 2
In this study, the patients' age ranged from 1 to 88 years, with a mean of 43 years $( \pm 17.2 \mathrm{SD})$, and a median of 46 years. The most common affected age groups were fifth and sixth decades including (23.6\%) and $(21.2 \%)$ of the patients respectively (Fig. 1).

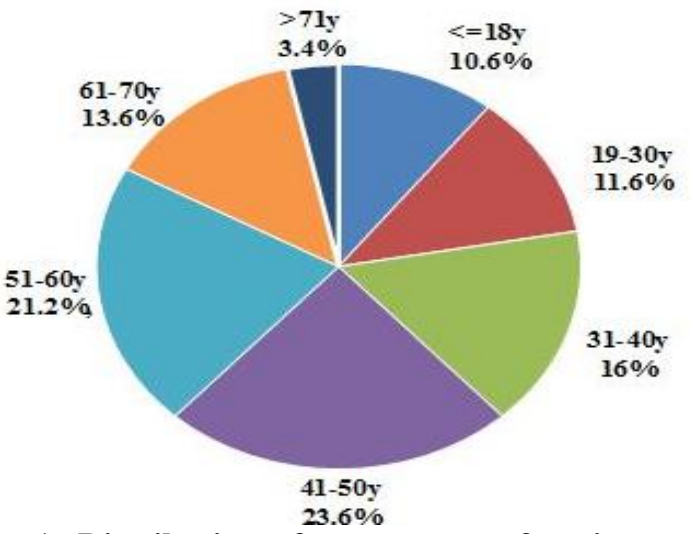

Fig. 1: Distribution of age groups of patients with primary central nervous system tumors

For detailed analysis, we categorized the patients into two groups according to age, the adult group, which included $(89.4 \%)$ of patients while the remainder $(10.6 \%)$ were among the pediatric group. (6.6\%) of pediatric group patients were less than 2 years

The most frequent tumors among adult population were meningiomas, gliomas and pituitary adenomas representing $(37.2 \%),(32.1 \%)$ and $(17.1 \%)$ of cases respectively. On the other hands, gliomas and embryonal tumors were the most common among pediatric group, accounting for $(59.4 \%)$ and $(17 \%)$ of tumors respectively, and the difference was highly significant statistically $(\mathrm{P}<0.01)$. (Table 1$)$. 


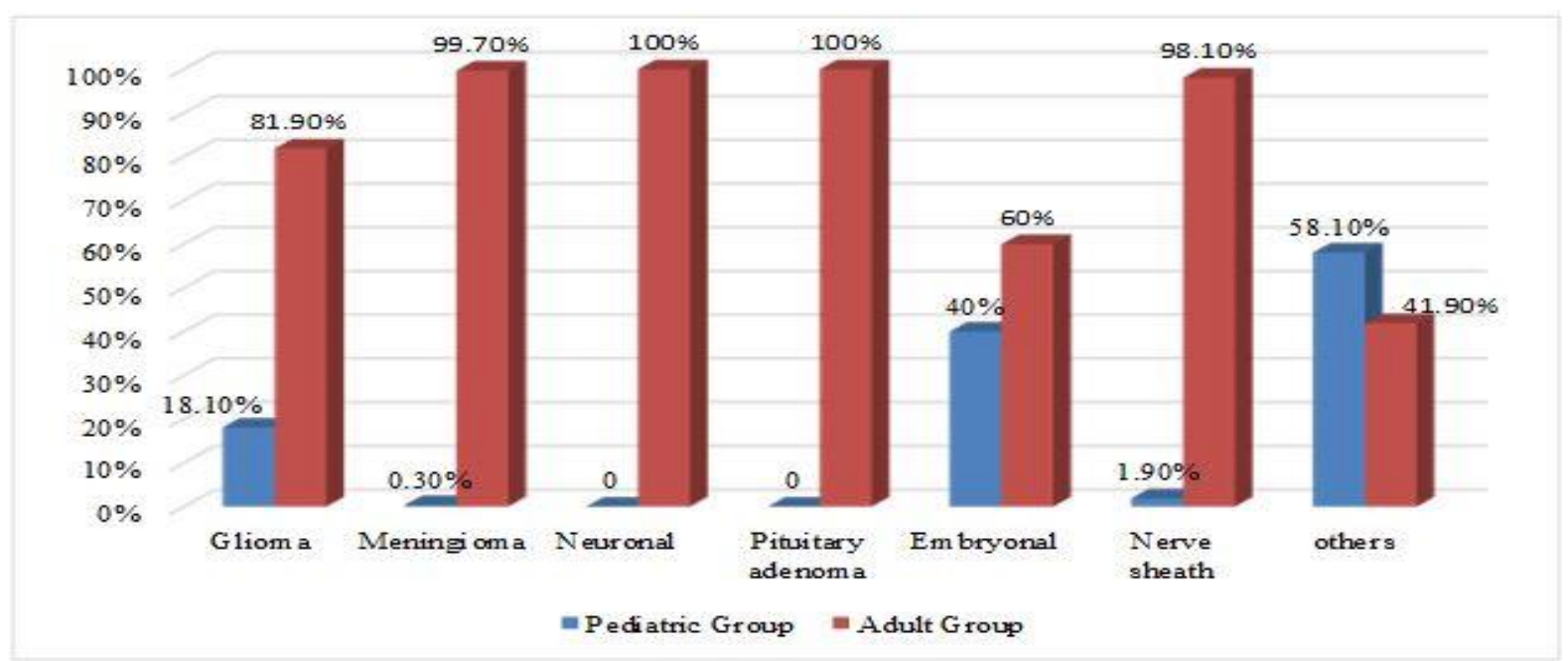

Fig. 2: Distribution of different CNS tumors among pediatric and adult age groups.

Distribution of Tumors According to Patient Gender

Males constituted (51.7\%) whereas females constituted $(49.3 \%)$ of our population. Gliomas were the most frequent among males $(42.9 \%)$, followed by meningiomas $(21.6 \%)$ and pituitary adenomas $(18.8 \%)$
On the other hand, meningiomas among female patients were the most common representing $(45.9 \%)$ of cases, followed by gliomas $(26.6 \%)$ and pituitary adenomas $(12.1 \%)$ and the difference was highly significant statistically (Table 2)

Table 2: Gender distribution of primary CNS tumors

\begin{tabular}{|l|c|c|c|c|c|c|c|c|c|}
\hline Gender & $\begin{array}{c}\text { Glioma } \\
\text { No. \% }\end{array}$ & $\begin{array}{c}\text { Meningioma } \\
\text { No. \% }\end{array}$ & $\begin{array}{c}\text { Mesenchymal } \\
\text { non mening } \\
\text { No. \% }\end{array}$ & $\begin{array}{c}\text { Lymphoid } \\
\text { No. \% }\end{array}$ & $\begin{array}{c}\text { Neuronal } \\
\text { No. \% }\end{array}$ & $\begin{array}{c}\text { Pituit } \\
\text { Adenoma } \\
\text { No. \% }\end{array}$ & $\begin{array}{c}\text { Embrynonal } \\
\text { No. \% }\end{array}$ & $\begin{array}{c}\text { Nerve s } \\
\text { health } \\
\text { No. \% }\end{array}$ & $\begin{array}{c}\text { Miscellaneous } \\
\text { No. \% }\end{array}$ \\
\hline $\begin{array}{l}\text { Male } \\
\text { N=515 }\end{array}$ & 22142.9 & 11121.6 & 40.8 & 112.1 & 51.0 & 9718.8 & 173.3 & 224.3 & 275.2 \\
\hline $\begin{array}{l}\text { Female } \\
\text { N=481 }\end{array}$ & 12826.6 & 22145.9 & 20.4 & 112.3 & 51.0 & 5812.1 & 142.9 & 275.6 & 153.1 \\
\hline
\end{tabular}

$\mathrm{X} 2=74.8 \quad \mathrm{P}=0.000$

Distribution of tumors according to location

(92.6\%) of tumors in this study were located in the brain, distributed as $(23.1 \%)$ in sellar and suprasellar location, $(18.3 \%)$ in frontal lobe, $(16.9 \%)$ in parietal lobe, $(10.7 \%)$ in posterior fossa and $(10.3 \%)$ in skull Base, arranged in descending order of frequency (Fig. $3)$.

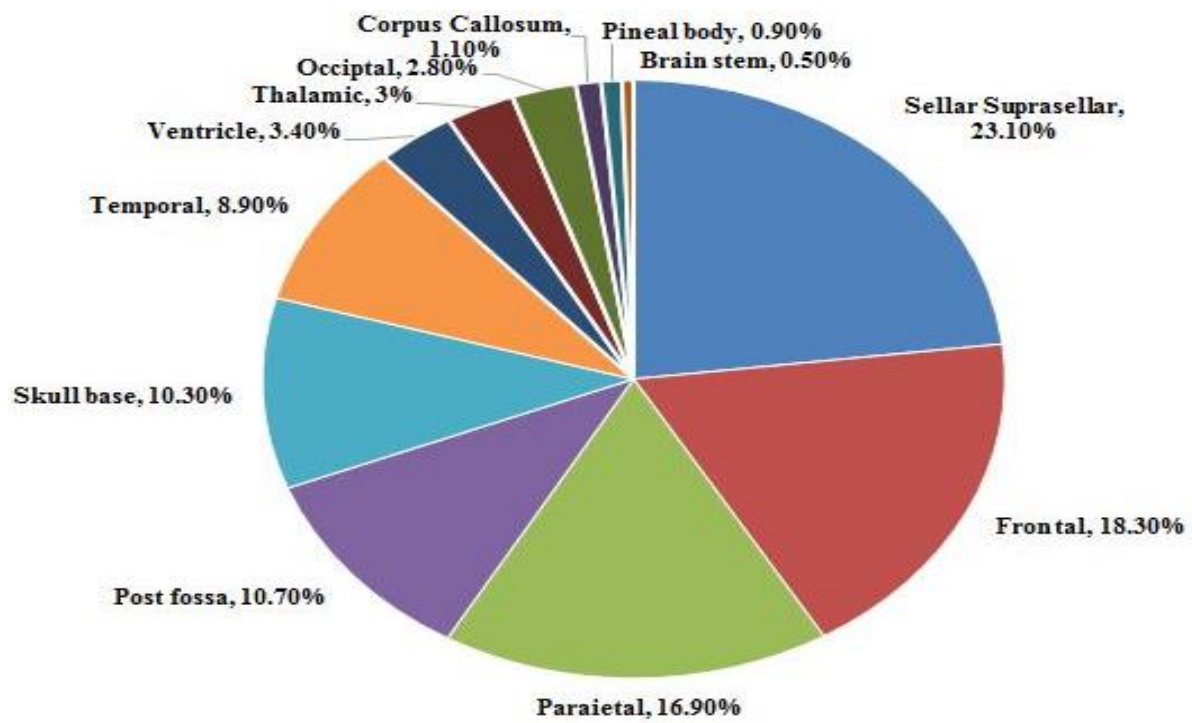

Fig. 3: Distribution of brain tumors according to anatomical location 
Spinal cord tumors represented only $(7.4 \%)$ of our cases, distributed as $(25.7 \%)$ cervical, (55.4\%) dorsal, (16.2\%) lumbar and (2.7\%) in sacral spine.

The tumors most frequently located in the brain were gliomas representing (36.6\%) of cases (Fig. 4) whereas nerve sheath tumors represented the most common tumors in the spinal cord (33.8\%) (Fig. 5).

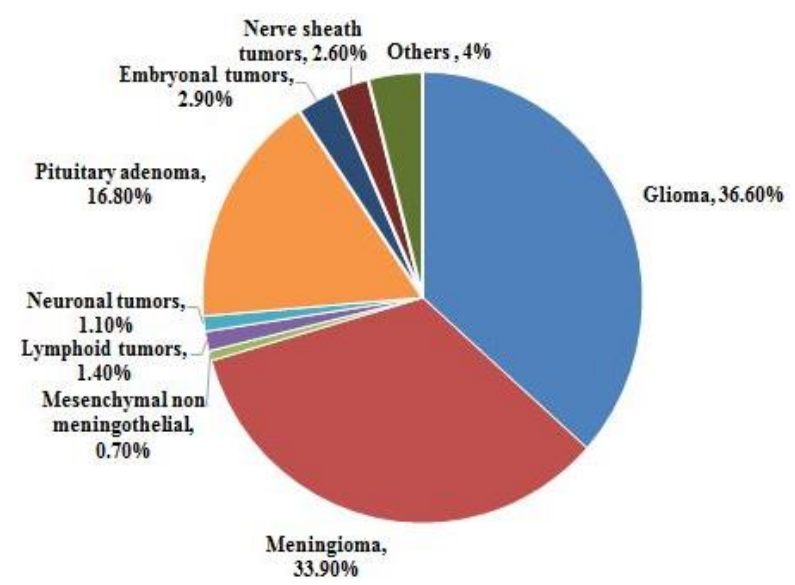

Fig. 4: Distribution of CNS tumors in the brain

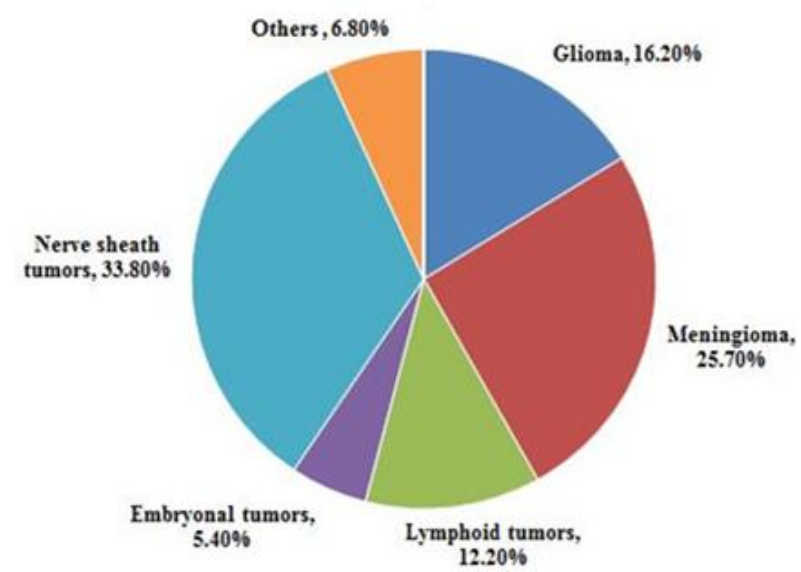

Fig. 5: Distribution of CNS tumors in the spinal cord

Among adult group, sellar/suprasellar (23.9\%), parietal $(18.8 \%)$ and frontal lobes $(18.1 \%)$ were the dominant locations for tumor occurrence. On the other hand, tumors of pediatric group were predominantly located at posterior fossa $(26.5 \%)$ followed by sellar/suprasellar sites (16.2\%).

Distribution of Tumors According to
Histopathologic types
Gliomas: Gliomas represented (35\%) of all tumors
included in this study, being the most common primary
CNS tumor in our population. The mean age for these
tumors was calculated as 40.6 years \pm 18.9 SD. $(81.9 \%)$
of gliomas occurred in the adult group, while $(18.1 \%)$
occurred among the pediatric population. Regarding sex

distribution; (63.3\%) of gliomas occurred among male patients while (36.7\%) occurred among females.

Regarding tumor location, (96.6\%) of gliomas were located in the brain, and only (3.4\%) in the spinal cord.

\section{Based on Histopathologic Aspect With No Further Molecular Testing, Gliomas in This Study Were Classified As Following:}

Diffuse Astrocytic and Oligodendroglial Tumors included diffuse astrocytoma WHO Grade П (16.9\%), anaplastic astrocytoma WHO Grade Ш (8\%), glioblastoma WHO Grade VI (44.1\%); representing the most common type, gliosarcoma WHO Grade VI $(0.9 \%)$, oligodendroglioma WHO Grade $\Pi(1.4 \%)$, anaplastic oligodendroglioma WHO Grade Ш $(0.6 \%)$, oligoastrocytoma WHO Grade П (3.2\%).

Other astrocytic tumors included pilocytic astrocytoma WHO Grade I representing (11.2\%) of cases, pilomyxoid astrocytoma WHO Grade $\Pi(1.1 \%)$, pleomorphic xanthoastrocytoma WHO Grade П (1.7\%) and subependymal giant cell astrocytoma WHO Grade I $(0.9 \%)$.

Ependymomas (8\%), In addition to other gliomas as astroblastoma (1.4\%), and chordoid glioma of the third ventricle WHO Grade $\Pi(0.3 \%)$.

\section{Meningiomas}

Meningioma constituted (33.3\%) of all included tumors, the mean age was estimated as 51 years \pm 12.4 $\mathrm{SD}$. These tumors were more commonly developing in females, with a percentage of $(66.6 \%)$, as compared to (33.4\%) in males. Regarding age group; $(99.7 \%)$ of meningioma occurred among adult patients, while only $(0.3 \%)$ occurred in pediatric group.

In the current study, meningioma displayed predilection to the brain $(94.2 \%)$ in contrast to minority of cases occurring in the spinal cord $(5.8 \%)$.

As for variants of meningioma, the predominant WHO grade I meningiomas were transitional representing $(53.1 \%)$ of all cases, followed by meningothelial (21.7\%), fibroblastic (4.8\%), psammomatous (6.6\%), angiomatous (3\%), microcystic (1.2\%), and metaplastic $(0.3 \%)$.

Regarding WHO grade $\Pi$ meningiomas, atypical meningiomas in addition to chordoid and clear cell meningiomas represented $(5.1 \%)$. Finally, anaplastic meningiomas constituted $(3 \%)$ of cases in addition to four cases of papillary meningioma (1.2\%), forming a total percentage of $(4.2 \%)$ for WHO grade Ш meningioma.

\section{Embryonal Tumors}

(3.1\%) of cases included in the current study belong to embryonal tumors. The mean age for these tumors was 18 years \pm 12.3 SD. Embryonal tumors displayed slight male predilection $(54.8 \%)$. Of these tumors, $(58.1 \%)$ occurred among pediatric patients; 
however $(41.9 \%)$ were found in adult group. (87\%) of embryonal tumors were located in the brain, in contrast to $(13 \%)$ of cases in the spinal cord.

Embryonal tumors included medulloblastomas which represented $(64.5 \%)$ of cases, CNS embryonal tumor, NOS (22.6\%), atypical teratoid rhabdoid tumor (6.5\%), CNS neuroblastoma (3.2\%) and medulloepithelioma (3.2\%), all are classified as WHO Grade VI.

\section{Neuronal and Mixed Glioneuronal Tumors}

This category formed only (1\%) of all tumors. The mean age was estimated as 26.5 years $\pm 12.1 \mathrm{SD}$. (60\%) of these tumors occurred in adults group, compared to $(40 \%)$ in pediatric group. Tumors having neuronal component were equally represented among males and females. Interestingly, all of these tumors were located in the brain.

Neurocytoma WHO Grade П represented (60\%) of neuronal tumors, while gangliogliomas WHO Grade I represented $(40 \%)$.

\section{Lymphomas}

Lymphomas constituted (2.2\%) of all tumors, the mean age is $51.2 \pm 11.9 \mathrm{SD}$. All Lymphomas occurred among adults. Moreover, all of them were located in the brain. Regarding gender distribution, they occurred equally among males and females. All lymphomas were Non-Hodgkin's diffuse large B cell type.

\section{Nerve Sheath Tumors}

$(4.9 \%)$ of tumors originated from nerve sheath in this study. The mean age of those patients was $42.7 \pm$ 16.7 SD. Of these tumors (95.9\%) presented in adults; while only $(4.1 \%)$ presented among pediatric patients. (44.9\%) of nerve sheath tumors occurred in males, while $(55.1 \%)$ were females. Regarding tumor location, they were almost equally distributed between brain and spinal cord, with estimated percentage of $(49 \%)$ and (51\%) respectively.

According to histopathology, schwannoma constituted the majority of the cases $(89.8 \%)$, while spinal neurofibromas represented (10.2\%).

\section{Pituitary Adenomas}

Pituitary adenomas represented the third common tumor in this study, accounting for (15.6\%) of all tumors. The mean age is $43.4 \pm 13.7 \mathrm{SD}$. These tumors occurred almost exclusively in adults, with only three cases in pediatric population representing only $(2 \%)$ of pituitary adenomas. They are located in the brain, in sellar and/or suprasellar region. (62.6\%) of pituitary adenomas occurred in males, in contrast to $(37.4 \%)$ in females.

Other tumors represented minority of cases in our study, accounting for (4.9\%), they included craniopharyngioma $(1.7 \%)$, hemangiopericytoma (1.3\%), hemangioblastoma (1\%), germ cell tumors
$(0.5 \%)$, choroid plexus papilloma $(0.2 \%)$ and pineal tumors $(0.2 \%)$.

\section{Discussion}

Estimation of primary CNS tumors frequency and distribution in a population has been always a subject of descriptive and analytical studies in order to characterize these relatively infrequent tumors and understand their biologic behavior and multifactorial variations.

We studied the frequency of primary CNS tumors together with age, gender, topographic distribution and histopathologic tumor types.

Among our study population, patient's age ranged from 1-88 years with a median age of 46 years, this is lower than results from United States (59 years) and Croatia (50.1 years). ${ }^{6-7}$ meanwhile, studies from China and Pakistan reported a lower median age (35years) and (40.1 years) respectively. ${ }^{8-9}$

The highest age group with affection of central nervous system tumors were patients in early 40's and 50 's, this finding comes in agreement with a report that was made on the analysis of brain and central nervous system cancer in the Middle East Cancer Consortium (MECC). ${ }^{10}$

In our analysis, males predominate, representing (51.7\%) of all cases which goes in agreement with some studies but differs from other studies including CBTRUS [central brain tumor registry of the United States] report. ${ }^{6-9}$ However in meningeal tumors, females outnumbered male patients, same results were mentioned in variable local ${ }^{11}$ and international studies. ${ }^{12-13}$

Gliomas represented the most common histologic tumor type among the study population, forming (35\%) of all cases, this is in agreement with krishnatreya et al, ${ }^{14}$ Bauchet et al, ${ }^{15}$ and Vovoras et al,. ${ }^{16}$ Also the middle Eastern cancer consortium reported Gliomas in Egypt represents $81.7 \%$ of the total brain tumors in Egypt. ${ }^{10}$ However, other studies including those done by Lee et $\mathrm{al}^{17}{ }^{1}$ and Ostrom et $\mathrm{al}_{,}{ }^{6}$ revealed a predominance of meningioma over other primary CNS tumors representing $(30.6 \%)$ and $(36.6 \%)$ of their overall cases respectively.

Data from the literature suggested that gliomas affect males more commonly than females ${ }^{18}$, this doesn't deviate from our results. Among gliomas, astrocytic neoplasms were the most frequent, glioblastoma constituted $(44.1 \%)$ of this category, a fact that is comparable to results from Austria and Malaysia. ${ }^{19-20}$ Noteworthy, oligodendroglial tumors represented only (2\%) of all glial tumors in this study, this is in concordance to results from the United States. ${ }^{6}$

Study of meningioma revealed a frequency of (33.3\%), this is slightly higher than results from Japanese, ${ }^{21}$ Pakistani, ${ }^{9}$ and French reports, ${ }^{22}$ with frequencies of $(27.1 \%),(28.3 \%)$ and $(28.8 \%)$ respectively. Female predilection and predominant 
benign histology are features concluded from our analysis, keeping with reviews of the literature. ${ }^{23}$

Of note, transitional variant was the most common of all meningioma $(53.1 \%)$ followed by meningothelial variant (21.7\%), while other reports revealed predominance of meningothelial meningioma over other variants. ${ }^{24-25}$ In regard to $\mathrm{WHO}$ grade $\Pi$ and $\amalg$ meningioma, they represented $(5.1 \%)$ and $(4.2 \%)$ of the cases respectively, these data differ from other reports. Colli and colleagues ${ }^{26}$ reported a frequency of $(8.2 \%)$ and $(1.7 \%)$ for grades $\Pi$ and $\amalg$, Desel and Patel reported similar frequencies. ${ }^{27}$

Among all studied cases, pituitary adenomas ranked as the third most common tumor, representing $(15.6 \%)$, a frequency that is lower than results from Japan brain tumors registry $(18.2 \%)^{28}$ and higher than data from Austria $(8.9 \%)^{19}$ and India $(8.3 \%){ }^{29}$

Embryonal tumors constituted (3.1\%) of our study population, this is comparable to results from Suh et al, $(2.7 \%)$ and Zalata et al, $(3.8 \%)^{8-10}$ and higher than figure reported by Ostrom et al (1.1\%). ${ }^{6}$ Medulloblastoma was the most frequent among these tumor $(64.5 \%)$ keeping with data from other reports. ${ }^{30}$ Our results revealed a striking difference in the frequency, topographic distribution and histopathologic tumor types between adult and pediatric patient groups. Most frequent tumors among adult group were meningioma $(37.2 \%)$, gliomas $(32.1 \%)$, and pituitary adenoma, this is comparable to data from the United States. ${ }^{31}$ where percentages of $(35.5 \%)$ and $(33.7 \%)$ were estimated for meningioma and gliomas respectively. Conversely, Chinese $^{32}$ and Pakistani 9 studies reported higher rates for gliomas over meningioma.

Regarding the most frequent pediatric tumors in our study, gliomas ranked firstly with a percentage of (59.4\%), followed by embryonal tumors (17\%) with a dominant contribution of medulloblastoma. These results are in agreement with several worldwide reports. ${ }^{33-35}$

Tumors of the posterior fossa were the most common among pediatric patients, while sellar and suprasellar tumor locations were dominant among adults in our population, these data didn't deviate from many reports. ${ }^{36}$

\section{Conclusion and Recommendations}

Our study has generated detailed information regarding the spectrum and prominent features of primary CNS tumors in a tertiary hospital. We recommend the establishment of specialized national center for CNS tumors in Egypt; this will provide efficient registry system and accurate data analysis for these tumors. Large scale studies should be conducted, aiming for understanding the trends and characteristics of CNS tumors in our country. The result of such work will have a direct impact on the services that are needed for the care of these patients.

\section{References}

1. Aloisi P, Martella F, Cerone D and Porzio G. Central Nervous System Tumors, in Biotargets of Cancer in Current Clinical Practice, M. Bologna, Editor. 2012 Humana Press: Totowa, NJ. p. 1-18.

2. Ibrahim A, Khaled H, Mikhail N, Baraka $\mathrm{H}$ and Kamel H. Cancer Incidence in Egypt: Results of the National Population-Based Cancer Registry Program. Journal of Cancer Epidemiology, 2014;18.

3. Katchy K, Alexander S, Al-Nashmi N and Ramadan A. Epidemiology of primary brain tumors in childhood and adolescence in Kuwait. Springerplus, 2013;2:58.

4. Fritz A, Percy C, Jack A, Shanmugaratnam K, Sobin L, Parkin DM et al., International Classification of Diseases for Oncology, third edition. Geneva, World Health Organization, 2000.

5. Louis DN, Ohgaki H, Wiestler OD and Cavenee WK. World Health Organization Histological Classification of Tumours of the Central Nervous System. International Agency for Research on Cancer, France, 2016.

6. Ostrom QT, Gittleman H, Xu M, Kromer C, Wolinsky Y, Kruchko C et al., CBTRUS Statistical Report: Primary Brain and Other Central Nervous System Tumors Diagnosed in the United States in 2009-2013. NeuroOncology, 2016;18: v1-v75.

7. Materljan E, Sepcić J, Tuskan-Mohar L, Zamolo G and Erman-Baldini I. Epidemiology of central nervous system tumors in Labin area, Croatia, 1974-2001. Croat Med J, 2004;45(2):206-12.

8. Suh Y, Koo H, Kim T, Chi J, Khang SK, Choe G et al. Tumors of the central nervous system in korea: a multicenter study of 3221 cases. J Neurooncol. 2002;56:251-9.

9. Ahsan J, Hashmi S, Muhammad I, Ud Din H, Butt AM, Nazir $S$ et al. Spectrum of central nervous system tumours-a single center histopathological review of 761 cases over 5 years. Journal of Ayub Medical College Abbottabad, 2015;27(1):81-84.

10. Inskip PD, Ron E: Brain and other central nervous tumor cancers, chapter 12, Middle East Cancer Constorium 2006. Accessed in April 2018 https://www.cabdirect.org/cabdirect/abstract/2008324100 0

11. Zalata K, El-Tantawy D, Abdel-Aziz A, Ibraheim A, Halaka AH, Gawish HH. et al. Frequency of central nervous system tumors in delta region, Egypt. Indian Journal of Pathology and Microbiology, 2011;54(2):299306.

12. Dobec-Meić B, Pikija S, Cvetko D, Turkulja V, Pazanin $\mathrm{L}$, Kudalic $\mathrm{N}$ et al., Intracranial tumors in adult population of the Varaždin County (Croatia) 1996-2004: a population-based retrospective incidence study. Journal of Neuro-Oncology, 2006;78(3):303-310.

13. Jazayeri S, Rahimi-Movaghar V, Shokraneh F, Saadat S and Ramezani R. Epidemiology of primary CNS tumors in Iran: a systematic review. Asian Pac J Cancer Prev, 2013; 14(6):3979-85.

14. Krishnatreya M, Kataki A, Sharma J, Batttacharyya M and Nandi P. Brief descriptive epidemiology of primary malignant brain tumors from North-East India. Asian Pac J Cancer Prev, 2014;15(22):9871-3.

15. Bauchet L, Rigau V, Mathieu-Daude H, FigarellaBranger D, Hugues D, Palusseau L et al. French brain tumor data bank: methodology and first results on 10,000 cases. 2007;84(2):189-99. 
16. Vovoras D, Pokhrel K and Tsokos C. Epidemiology of Tumors of the Brain and Central Nervous System: Review of Incidence and Patterns among Histological Subtypes. Open Journal of Epidemiology, 2014;4(04):224.

17. Lee C, Jung KW, Yoo H, Park S and Hoon S. Epidemiology of Primary Brain and Central Nervous System Tumors in Korea. J Korean Neurosurg Soc, 2010;48(2):145-52.

18. Butowski N and Chang S. Glial tumors: the current state of scientific knowledge. Clin Neurosurg, 2006;53:106-13.

19. Wohrer A, Waldhör T, Heinzl H, Hackl M, Feichtinger J, Gruber Mösenbacher U et al. The Austrian Brain Tumour Registry: a cooperative way to establish a populationbased brain tumour registry. J Neurooncol, 2009;95(3):401-11.

20. Goh CH, Lu YY, Lau BL, Wong JO, Lee HK, Sanliew $\mathrm{DN}$ et al. Brain and spinal tumour. Med J Malaysia, 2014;69(6):261-7.

21. Nomura K. Present status of brain tumor statistics in Japan. International Journal of Clinical Oncology, 2000;5(6):355-360.

22. Rigau, V, Zouaoui S, Mathieu-Daudé H, Darlix A, Maran A, Trétarre B, et al. French brain tumor database: 5-year histological results on 25756 cases. Brain Pathol, 2011;21(6):633-44.

23. Louis DN, Ohgaki H, Wiestler OD and Cavenee WK. Chapter 10: Meningioma, World Health Organization Histological Classification of Tumours of the Central Nervous System, 2016;232-245.

24. Samadi N and Ahmadi SA. Meningioma: a clinicopathological evaluation. Malays J Med Sci, 2007;14(1):46-52.

25. Lakshmi S. Meningiomas: A clinicopathological study. International Journal of Medical Research \& Health Sciences, 2015;4(4):827-831.

26. Colli BO, Carlotti CC, Assirati JA, Coelho VM and Neder L. Atypical and anaplastic meningiomas in a public hospital in São Paulo State, Brazil. Arquivos de Neuro-Psiquiatria, 2015;73:770-778.
27. Desai P and Patel D. Histopathological study of meningioma. International Journal of Medical Science and Public Health. 2012;1(5):327-330.

28. Shibui $S$. The present status and trend of brain tumors based on the data of the Brain Tumor Registry of Japan. Brain Nerve, 2012;64(3):286-90.

29. Jalali R and Datta D. Prospective analysis of incidence of central nervous tumors presenting in a tertiary cancer hospital from India. J Neurooncol, 2008;87(1):111-4.

30. Johnson KJ, Cullen J, Barnholtz-Sloan JS, Ostrom QT, Langer CE, Turner MC et al. Childhood brain tumor epidemiology: a brain tumor epidemiology consortium review. Cancer Epidemiology and Prevention Biomarkers, 2014; p. cebp. 0207.2014.

31. Dolecek TA, Propp JM, Stroup NE and Kruchko C. CBTRUS Statistical Report: Primary brain and central nervous system tumors diagnosed in the United States in 2005-2009. Neuro Oncol. 2012;14(Suppl 5):v1-v49.

32. Chen L, Zou X, Wang Y, Mao Y and Zhou L. Central nervous system tumors: a single center pathology review of 34,140 cases over 60 years. BMC Clin Pathol, 2013;13(1): 14 .

33. Lannering B, Sandström PE, Holm S, Lundgren J, Pfeifer $\mathrm{S}$, Samuelsson U et al. Classification, incidence and survival analyses of children with CNS tumours diagnosed in Sweden 1984-2005. Acta Paediatr, 2009;98(10):1620-7.

34. Wong TT, Ho DM, Chang KP, Yen SH, Guo Wy, Chang FC et al. Primary pediatric brain tumors: statistics of Taipei VGH, Taiwan (1975-2004). Cancer, 2005;104(10):2156-67.

35. Cho KT., Wang KC., Kim SK., Shin SH., Chi JG and Cho BK. Pediatric brain tumors: statistics of SNUH, Korea (1959-2000). Childs Nerv Syst, 2002;18(1-2):30-7.

36. Plowman P and Brada M. Paediatric brain tumours. British medical bulletin, 1996;52(4):802. 